\title{
Editorial Volume 14
}

\author{
Sabina W. Lautensach ${ }^{1,2,3}$ \\ ${ }^{1}$ Editor-in-Chief of the Journal of Human Security, Librello, Basel, Switzerland \\ 2 Human Security Institute, Canada \\ 3 University of Northern British Columbia, Terrace, BC, V8G 4A2, Canada; E-Mail: salaut@gmail.com
}

Published: 7 May 2018

Dear Reader,

"Are we nuts?" asked recently one of my favourite bloggers. She was referring to human behaviour that contravened the actor's own explicit interests, as routinely reported in a cross-section of the average daily news. Her deceivingly simple question can be interpreted at the individual level (e.g. junk food) and the collective levels (e.g. gun use), applied to the short or longer term, to human nature as it manifested historically or to human behaviour at the present time. Her question could also have been directed at events not usually covered by the mainstream media, such as ecology and population issues, or the fact that the world's most powerful country is now governed by a kakistocracy $[1,2]$. But even without singling out its worst offenders, collective policies around the world show a deplorable lack of scientific reason [3].

The symptoms that many societies use to define mental illness tend to address the extent to which a person's behaviour represents a threat to security (including their own), as do the criteria that have to be met in order to have a person committed to a psychiatric institution. According to the WHO and the American Psychiatric Association, those criteria for psychopathology include the following:

- Callous unconcern for the feelings of others

- Incapacity to maintain enduring relationships

- Reckless disregard for the safety of others

- Deceitfulness, repeated lying and conning others for personal gain

- Incapacity to experience guilt

- Failure to conform to social norms with respect to lawful behaviours

Applied to individual behavior, those criteria intuitively make sense - at least they conform to standards of sanity or 'civilised' behavior that are broadly held in many societies and are reflected in their laws. It therefore came as a surprise when the documentary "The Corporation" [4] proposed that large corporations typically do not meet those standards. The authors concluded that a corporation, inasmuch as its conduct is to be assessed as that of an individual, couldn't qualify for civic rights and legal status of personhood on account of insanity. While many citizens have long felt distrustful of the 'ethics' displayed by large corporations, and therefore looked upon corporate claims of legal personhood with some skepticism, the extent to which corporate behavior met the criteria for mental insanity came as a surprise.

Looking beyond corporations-in the context of the blogger's question one wonders to what extent the behavior and policies of other groups and organisations, even entire societies, violate the standards of sanity. And if they are found wanting, how should societies react? What are the available recourses to address the concomitant threats to human security?

As far as collective behavior at the global level is concerned, three high-profile approaches for investigation have attracted worldwide attention, not least because they put into question our assumptions of collective sanity. One line arose from the work done by researchers around Mathis Wackernagel for the Global Footprint Network and the World Wildlife Fund [5]. It substantiated the evidence of a massive ecological overshoot at the global level, expressed as the ratio of human environmental impact or demand over the global capacity of the biosphere to support it, reaching 1.6 in 2016 [5]. This line of inquiry rests on the concept of the 
ecological footprint that emerged in the 1990s, and on the early publications by the Club of Rome beginning with its Limits to Growth [6].

The second approach culminated in the latest (second) warning by over fifteen thousand of the world's scientists, emphasizing the overwhelming evidence that current policies and trends around the world are unsustainable and will lead to disastrous consequences [7] It takes a broader perspective, examining extents and trends of ecosystem deterioration, loss of agricultural productivity, pollution levels, extraction of renewable and non-renewable resources and loss of biodiversity.

The third approach, by researchers around Johan Rockström at the Stockholm Resilience Centre [8], compares anthropogenic global change with quantitative limits of sustainability. It centers on a descriptive model that features nine planetary environmental boundaries that limit sustainable human impacts on the biosphere, thus describing in an impressive graphical representation what 'safe operating space' remains with respect to those nine impact areas. As of yet, human impacts have transgressed four of those boundaries (climate change, loss of biosphere integrity, land-system change, altered biogeochemical cycles of phosphorus and nitrogen), three are being approached (ozone depletion, ocean acidification and freshwater use) and two areas remain to be assessed (atmospheric aerosols and chemical pollution). This model integrated large amounts of data from independent measurements of human activities and compared them to what levels are globally sustainable, i.e. can be compensated by the capacity of the planetary ecosystem.

The boundary model was further expanded to take into account the sociopolitical, cultural and health-related pillars of human security by the work of Kate Raworth for Oxfam $[9,10]$. Its graphical representation takes the shape of a ring, widely referred to as the 'Oxfam Donut'. Its outer perimeter is determined by Rockström et al's nine environmental boundaries while its inner perimeter is formed by twelve minimum demands of social welfare (food, health, education, income \& work, peace \& justice, political voice, social equity, gender equality, housing, networks, energy, water). In between lies the 'safe and just' operating space for humanity, delimited by sufficiency in the social justice categories and by restraint regarding the environmental boundaries. While the underlying metrics continue to be refined, the conceptual impact of the donut model presents a breakthrough in our understanding of human security. It allows us for the first time to examine all ways in which human endeavours impact our planetary support system, to locate areas where further increases might be safe, and where existing transgressions are unsafe, and to compare those impact levels against the requirements for the just, safe and acceptable survival of our species [11].

This new understanding of human security replaces earlier conceptions of sustainability such as the excessively vague Brundtland formulation and the conceptually misleading Triple Bottom Line model. It enshrines the undeniable primacy of environmental sustainability over economic considerations while recognizing the normative demands of universal human rights and social justice for all. Thus, the four pillars of human security (sociopolitical, health-related, economic and environmental security) are effectively integrated under the umbrella of a model that unites the realm of the possible with the realm of the desirable. It helps to identify sources of insecurity in areas where boundaries are transgressed or where minimal demands remain unmet. It emphasizes the overriding imperative of operating within global boundaries without precluding the development of regional and local strategies to achieve them. It helps us to clarify what real international development must achieve in terms of human security goals, how it can avoid detrimental growth where it would exacerbate problems, and how some of the world's least 'developed' countries can show us the way [12]. A recent comparative international study of 145 countries suggested poor performance overall but also identified some moderately developed countries (led by Vietnam) as the global top achievers in 'keeping within the donut' [13]. It is to be hoped that the model will also provide some pointers for the 'Great Transition'-how global overshoot can be reduced with a minimum of sacrifice on the social welfare side, and how welfare can be increased above the acceptable minimum without further increasing our demands on the biosphere.

Most of these analyses originated from a global perspective, which in many respects is still the most relevant, as it is the global dimension that most clearly exhibits hard physical limits. However, both footprint accounting and boundary analysis have been extended into the regional and local dimensions. As mentioned above, comparisons of countries and regions provide valuable insights for revising development strategies. Schoolchildren now determine their environmental impact (and that of their families) through internet-based personal footprint calculators in order to find more sustainable ways of living. At the individual level the amount of initiative, approaches and advocacy towards a Great Transition is evidently increasing fast and growing into a global popular movement-against a background of millions of consumers who sadly remain uncommitted, uninformed or unaware.

At the communal level, encouraging case examples are reported (such as achieving energy autonomy [14]). At the national level, progress seems generally much slower, despite some individual strategic turnarounds such as in China [15]. In those cases, reform is pioneered by the initiatives and leadership of forward-looking individuals. The greatest obvious gap in getting an effective and all-encompassing Transition on its way appears at the levels of collective behaviour or governance.

Returning to my original question of assessing our sanity, one wonders to what extent a lack of sanity might be responsible for the widespread shortfall in transformative behaviour change. As far as individual behaviour is concerned, much of it certainly qualifies as irrational-the myth of the rational actor has long been debunked in academic 
circles outside of business schools. As individuals our behaviour tends to be informed primarily by attitudes, ideals, unexamined beliefs and assumptions, and values that are implicit and culturally contingent $[3,16]$.

In contrast, the behavior of large groups often comes across as frightfully base, unpredictable and thoughtlesswitness football mobs or stampeding devotees at religious events. Even more tightly organized groups such as communities and countries tend to behave, and to govern themselves, in ways that threatens their own safety, as suggested by the descriptive analyses summarized above (witness the dogged persistence of governments in subsidizing the fossil fuel industry). From the onset of global overshoot in the 1980s analysts explored the driving forces behind self-endangering collective behavior; they identified five self-reinforcing processes-economic growth, population growth, technological change, economic inequality and militarisation [17]. Those drivers are often invoked by individuals claiming that they 'had no choice' but to make counterproductive policy decisions. But does any of that behavior meet the criteria for insanity?

The list of psychopathology criteria provides several normative principles, if only from a consequentialist perspective. They include the avoidance of harm, empathy for the welfare of others, and social justice. The application of descriptive security models such as footprint accounting and boundary analysis shows that many of the world's individuals and most of its countries are not acting in accordance with those principles, often even explicitly denying their relevance. Does that satisfy the conditions for a diagnosis of insanity? Should the explicit advocacy of the values of modernity, neoliberalism and neoclassical economics count as indicative of having lost one's marbles?

Help in this bothersome dilemma comes from the unlikely direction of population biology. Many animal popula-

\section{References and Notes}

[1] Ehrlich P, Harte J. Pessimism on the Food Front. Sustainability. 2018;10(4):1120. doi:10.3390/su10041120.

[2] Wikipedia defines a kakistrocacy as "a system of government which is run by the worst, least qualified, or most unscrupulous citizens"; from Greek kakistos = worst, superlative of kakos = bad.

[3] Rees W. The Roots of Our Crises: Does Human Nature Drive Us toward Collapse? In: Lerch D, editor. The Community Resilience Reader. Island Press/Center for Resource Economics; 2017. pp. 111-127. 10.5822/978-1-61091-861-9_7.

[4] Bakan J. he Corporation: The Pathological Pursuit of Profit and Power. Toronto, Canada: Viking Canada; 2004.

[5] Living Planet Report. Gland, Switzerland: World Wildlife Fund; 2016. Available from: http://www.wwf.ca/newsroom/reports/wwf living_planet_report_2016.cfm.

[6] Meadows D, Randers J, Meadows D. The limits to growth: the 30-year update. White River Junction, VT, USA: Chelsea Green Publishing Co; 2012.

[7] Ripple WJ, Wolf C, Newsome TM, Galetti M, Alamgir M, Crist E, et al. World Scientists' Warning to Humanity: A Second Notice. BioScience. 2017;67(12):1026-1028. doi:10.1093/biosci/bix125.

[8] Rockström J, Steffen W, Noone K, Persson A, Chapin III FS, Lambin EF, et al. A safe operating space for humanity. nature. tions routinely push against environmental boundaries and often transgress them temporarily. They do so because they are adapted to utilizing available resources as efficiently as possible, which maximizes their reproductive fitness. But those periods of all-out growth are short-lived in comparison to the norm, which is characterized by an equilibrium of relatively constant numbers, mortality balancing fertility, and staying below critical boundaries. The global human population is no exception, as through most of our evolutionary past our numbers remained fairly constant. Only in the past three centuries did obvious exponential growth become evident, and the 'Great Acceleration' [18] is no more than seventy years old. In other words, the present chapter in human history with its unprecedented massive challenges to human security is a wild exception! From that perspective our species does not seem so fundamentally different from other animals-and surely we cannot all be chronically insane in the animal kingdom.

The possibility of a momentary (on the historical timescale) lapse of collective reason is another matter. Ideological driving forces, anachronistic education systems, powerful influences through media and entertainment industries, and counterproductive social norms can conspire to perpetuate a lemming-like behavior of large groups that is likely to hold us back for years to come. But insane it is not, I would argue-it is merely indicative of our mammalian nature while calling into question the high aspirations behind our species name.

That leaves us with the challenge to cope with our way down into the donut, to make it as prosperous as Howard and Elisabeth Odum [19] had hoped, and to hold on to our sanity come what may.

Best wishes, Sabina

9] Raworth K. A Doughnut for the Anthropocene: humanity's compass in the 21st century. The Lancet Planetary Health. 2017;1(2):e48e49. doi:10.1016/S2542-5196(17)30028-1.

[10] Raworth K. Doughnut economics: seven ways to think like a 21stcentury economist. Chelsea Green Publishing; 2017.

[11] Potter VR. Global Bioethics: Building on the Leopold Legacy. East Lansing, MI, USA: Michigan State University Press; 1988.

[12] Lautensach A, Lautensach S. Assessing the Top Performers: Mindful Conservatism and 'Sustainable Development'. In: Proceedings of The 3rd World Sustainability Forum. MDPI; 2013. Available from: https://doi.org/10.3390\%2Fwsf3-f004. 10.3390/wsf3-f004.

[13] O'Neill DW, Fanning AL, Lamb WF, Steinberger JK. A good life for all within planetary boundaries. Nature Sustainability. 2018;1(2):88-95. doi:10.1038/s41893-018-0021-4.

[14] Chakrabortty A. How a small town reclaimed its grid and sparked a community revolution. The Guardian. 2018 Feb;Note: The example of the small German town of Wolfshagen illustrates a communitybased approach to initiating a Great Transition. Available from: https://www.theguardian.com/commentisfree/2018/feb/28/smalltown-wolfhagen-community-revolution-german-europe-energycontract?CMP=share_btn_fb. Note: The example of the small German town of Wolfshagen illustrates a community-based approach to initiating a Great Transition. 
[15] Lent J. What Does China's 'Ecological Civilization' Mean for Humanity's Future? Mother Pelican. 2018;14(3). Available from: http://www.pelicanweb.org/solisustv14n03page6.html.

[16] Bolderdijk JW, Steg L, Geller ES, Lehman PK, Postmes T. Comparing the effectiveness of monetary versus moral motives in environmental campaigning. Nature Climate Change. 2012;3(4):413-416. doi:10.1038/nclimate1767.

[17] Daly HE, Cobb JB. For the common good: Redirecting the economy toward community, the environment, and a sustainable future. 73 . Boston, MA, USA: Beacon Press; 1994.

[18] Steffen W, Broadgate W, Deutsch L, Gaffney O, Ludwig C. The trajectory of the Anthropocene: The Great Acceleration. The Anthropocene Review. 2015;2(1):81-98. doi:10.1177/2053019614564785.

[19] Odum HT, Odum EC. A prosperous way down: principles and policies. Louisville, CO, USA: University Press of Colorado; 2008. 